\title{
Design of a Static VAR Compensator Using Model Reference Adaptive Control
}

\author{
YUAN-YIH HSU and CHIN-HSING CHENG \\ Department of Electrical Engineering, National Taiwan University, Taipei (Taiwan)
}

(Received August 13, 1987)

\section{SUMMARY}

A novel approach for the design of a static $V A R$ compensator (SVC) is proposed. The $S V C$, which comprises a fixed capacitor and a thyristor-controlled inductor, can be used to improve generator damping without deterioration in the voltage profile under severe disturbance conditions. In order to achieve better dynamic performance, a supplementary proportional-integral (PI) controller, of which the parameters are determined by eigenvalue assignment, is incorporated in the static VAR compensator. To further improve the damping characteristics over a wide range of operating conditions, an adaptive controller using model reference adaptive control (MRAC) is also developed. Results from the digital simulation of the system subject to a three-phase fault indicate that the MRAC can provide better dynamic performance than the fixed-gain PI controllers.

\section{INTRODUCTION}

During the past two decades, various damping schemes such as power system stabilizers [1 - 7] and static VAR compensators (SVCs) [8 - 14] have been developed to improve power system dynamic stability which has deteriorated by the widespread use of long transmission lines and static excitation systems. Among the supplementary controllers presented so far, the SVC will be examined in this paper.

In the literature, SVCs have been applied successfully to suppress arc furnace flicker [15], to regulate the voltage of transmission systems $[16,17]$, to improve transmission capacity [18], and to improve the transient stability of the synchronous machine [19 21]. The applications of static VAR systems to damp out machine oscillations are rather limited [8 - 14].

The purpose of this paper is to present a new approach for the design of an SVC to improve the damping characteristics of a synchronous machine. The proposed technique makes use of a proportional-integral (PI) controller which is the most commonly used control algorithm in the process industry. In order to achieve good dynamic performance over a wide range of operating conditions, the fixed-gain PI controller is further extended by an adaptive control algorithm called the model reference adaptive control (MRAC). For purposes of comparison, the dynamic responses following a major disturbance achieved by employing the proposed PI static VAR controller are compared with those obtained by using an MRAC SVC. It is found that the MRAC SVC can produce better dynamic responses than the fixed-gain PI SVC.

\section{MATHEMATICAL MODEL}

Figure 1 shows the schematic diagram for a synchronous generator equipped with an SVC. By adjusting the firing angles of thyristors

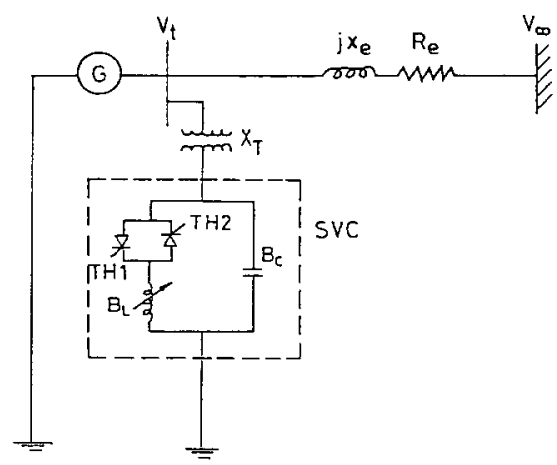

Fig. 1. Schematic diagram of a synchronous generator equipped with a static VAR compensator. 
TH1 and TH2 according to the variations in terminal voltage $V_{\mathrm{t}}$ and angular speed $\omega$, the susceptance of the inductor $B_{L}$ can be regulated as shown in Fig. 2 [13]. It should be noticed that in Fig. $2 K_{\mathrm{P}}$ and $K_{\mathrm{I}}$ are the parameters of the PI controller which are determined in the next section using the eigenvalue assignment method.

In the simulation of system dynamic performance under major disturbance conditions, a set of nonlinear differential equations describing the behavior of the generator and

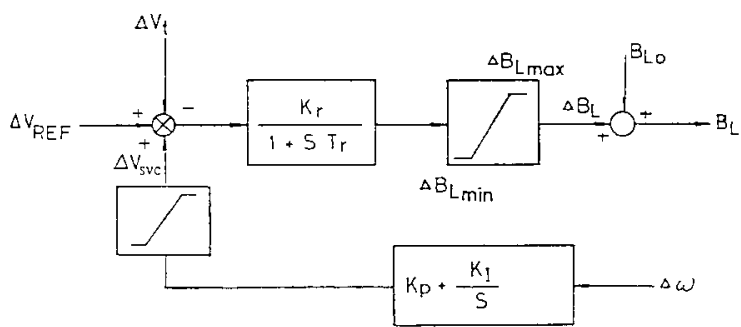

Fig. 2. Block diagram of the PI static VAR controller.

the SVC is required. These equations are given as follows.

The synchronous machine and SVC equations in per unit form in terms of Park's $d, q$ axes are $[1,13]$

$$
V(t)=\mathbf{K}(x, t) X(t)+\mathbf{M}(\boldsymbol{x}, t) \dot{X}(t)
$$

where

$$
\begin{aligned}
& V=\left[\begin{array}{lllllllllll}
\sqrt{3} V_{\infty} \sin \delta & 0 & 0 & -\sqrt{3} V_{\infty} \cos \delta & 0 & T_{\mathrm{m}} & 1 & V_{\mathrm{REF}}-V_{\mathrm{t}} & 0 & 0 & 0
\end{array}\right. \\
& \left.\Delta V_{\mathrm{REF}}+V_{\mathrm{s}}-\Delta V_{\mathrm{t}}\right]^{\mathrm{T}}
\end{aligned}
$$$$
X=\left[\begin{array}{llllllllllll}
i_{\mathrm{d}} & i_{\mathrm{F}} & i_{\mathrm{D}} & i_{\mathrm{q}} & i_{\mathrm{Q}} & \omega & \delta & V_{\mathrm{ST}} & E_{\mathrm{FD}} & i_{B \mathrm{~d}} & i_{B \mathrm{q}} & \Delta B_{L}
\end{array}\right]^{\mathrm{T}}
$$

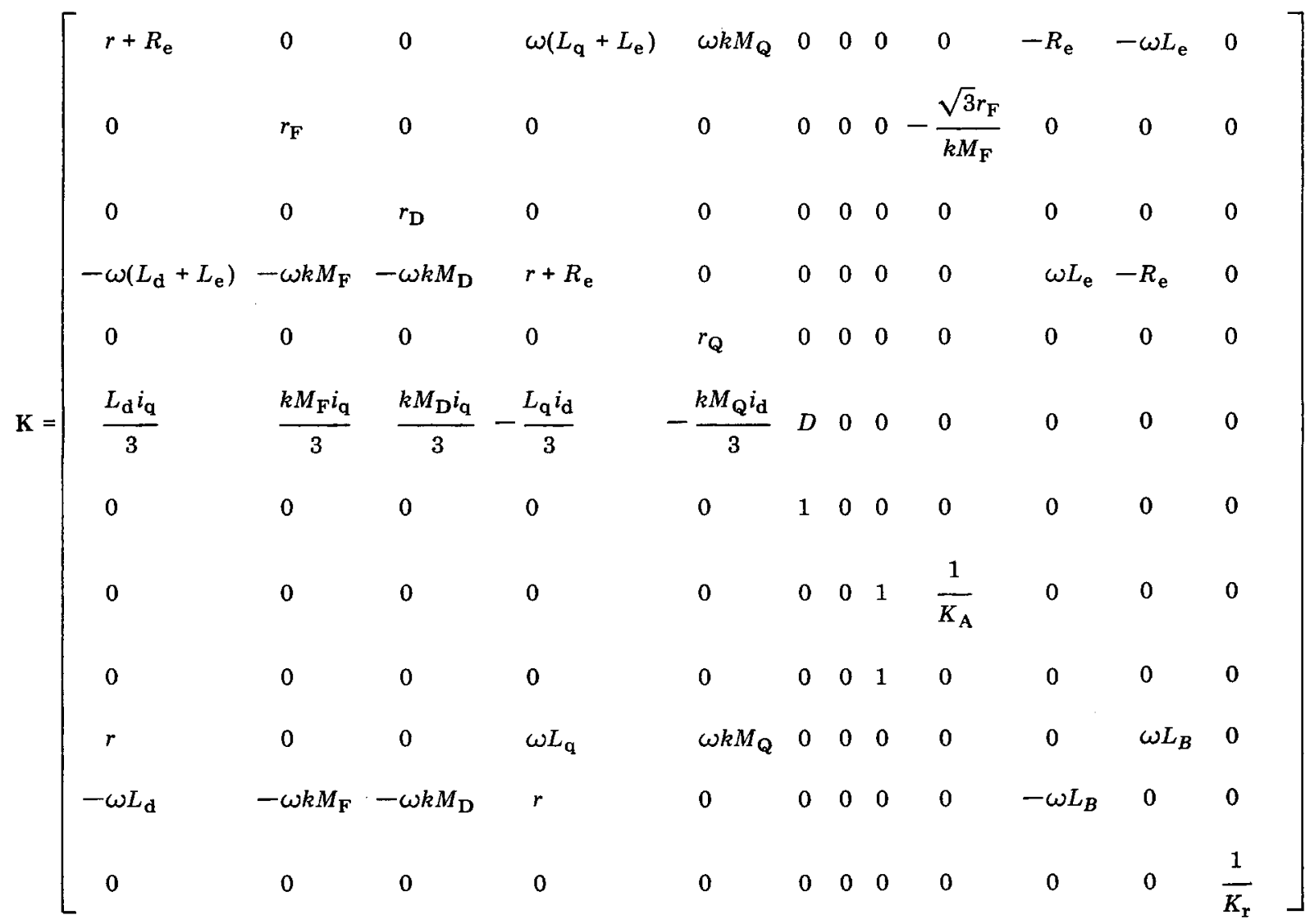


$\mathbf{M}=\left[\begin{array}{llllllllllll}L_{\mathrm{d}}+L_{\mathrm{e}} & k M_{\mathrm{F}} & k M_{\mathbf{D}} & 0 & 0 & 0 & 0 & 0 & 0 & -L_{\mathrm{e}} & 0 & 0 \\ k M_{\mathbf{F}} & L_{\mathrm{F}} & M_{\mathrm{R}} & 0 & 0 & 0 & 0 & 0 & 0 & 0 & 0 & 0 \\ k M_{\mathbf{D}} & M_{\mathrm{R}} & L_{\mathrm{D}} & 0 & 0 & 0 & 0 & 0 & 0 & 0 & 0 & 0 \\ 0 & 0 & 0 & L_{\mathrm{q}}+L_{\mathrm{e}} & k M_{\mathbf{Q}} & 0 & 0 & 0 & 0 & 0 & -L_{\mathrm{e}} & 0 \\ 0 & 0 & 0 & k M_{\mathbf{Q}} & L_{\mathbf{Q}} & 0 & 0 & 0 & 0 & 0 & 0 & 0 \\ 0 & 0 & 0 & 0 & 0 & \tau_{\mathrm{j}} & 0 & 0 & 0 & 0 & 0 & 0 \\ 0 & 0 & 0 & 0 & 0 & 0 & -1 & 0 & 0 & 0 & 0 & 0 \\ 0 & 0 & 0 & 0 & 0 & 0 & 0 & 0 & \frac{T_{\mathrm{A}}}{K_{\mathrm{A}}} & 0 & 0 & 0 \\ L_{\mathrm{d}} & k M_{\mathrm{F}} & k M_{\mathbf{D}} & 0 & 0 & 0 & 0 & 0 & 0 & L_{B} & 0 & 0 \\ 0 & 0 & 0 & L_{\mathbf{q}} & k M_{\mathbf{Q}} & 0 & 0 & 0 & 0 & 0 & L_{B} & 0 \\ 0 & 0 & 0 & 0 & 0 & 0 & 0 & 0 & 0 & 0 & 0 & \frac{T_{\mathbf{r}}}{K_{\mathbf{r}}}\end{array}\right]$

and

$V_{\mathrm{t}}=\left[\left(v_{\mathrm{d}}{ }^{2}+v_{\mathrm{q}}{ }^{2}\right) / 3\right]^{1 / 2}$

$L_{B}=X_{\mathrm{T}}-\frac{1}{B_{C}+B_{L}}$

$B_{L}=B_{L 0}+\Delta B_{L}$

In the design of the PI static VAR controller using the eigenvalue assignment method, the nonlinear differential equations have to be first linearized around a nominal operating condition of the synchronous machine to obtain the desired state equations:

$\dot{X}(t)=\mathrm{A} X(t)+\mathrm{B} U(t)+\Gamma z(t)$

$Y(t)=\mathbf{C X}(t)$

where

$\boldsymbol{X}=\left[\begin{array}{llllllllllll}\Delta i_{\mathrm{d}} & \Delta i_{\mathrm{F}} & \Delta i_{\mathrm{D}} & \Delta i_{\mathrm{q}} & \Delta i_{\mathrm{Q}} & \Delta \omega & \Delta \delta & \Delta V_{\mathrm{ST}} & \Delta E_{\mathrm{FD}} & \Delta i_{B \mathrm{~d}} & \Delta i_{B \mathrm{q}} & \Delta B_{L}\end{array}\right]^{\mathrm{T}}$ is the state vector

$z=\left[\begin{array}{ll}V_{\mathrm{REF}} & T_{\mathrm{m}}\end{array}\right]^{\mathrm{T}}$

is the disturbance vector,

$\mathbf{B}=\mathbf{M}^{-1} \mathbf{B}^{\prime} \quad$ and $\quad \mathbf{\Gamma}=\mathbf{M}^{-1} \boldsymbol{\Gamma}^{\prime}$

$\mathbf{B}^{\prime}=\left[\begin{array}{llllllllllll}0 & 0 & 0 & 0 & 0 & 0 & 0 & 0 & 0 & 0 & 0 & 1\end{array}\right]^{\mathrm{T}}$

$\boldsymbol{\Gamma}^{\prime}=\left[\begin{array}{lllllrllllll}0 & 0 & 0 & 0 & 0 & 0 & 0 & 1 & 0 & 0 & 0 & 1 \\ 0 & 0 & 0 & 0 & 0 & -1 & 0 & 0 & 0 & 0 & 0 & 0\end{array}\right]^{\mathrm{T}}$

$\mathrm{C}=\left[\begin{array}{llllllllllll}0 & 0 & 0 & 0 & 0 & 1 & 0 & 0 & 0 & 0 & 0 & 0\end{array}\right]$

$\mathbf{A}=-\mathbf{M}^{-1} \mathbf{K}$ 


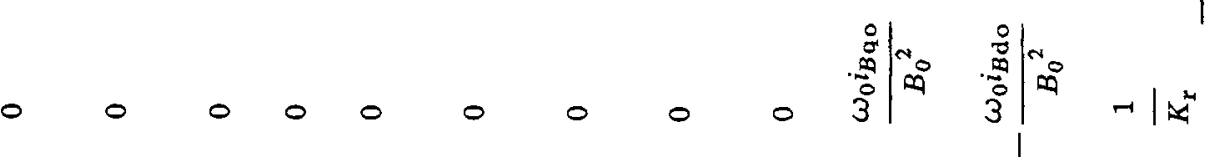

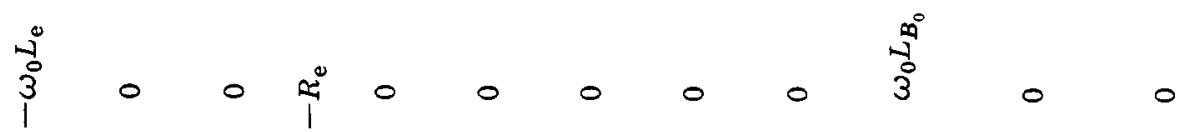

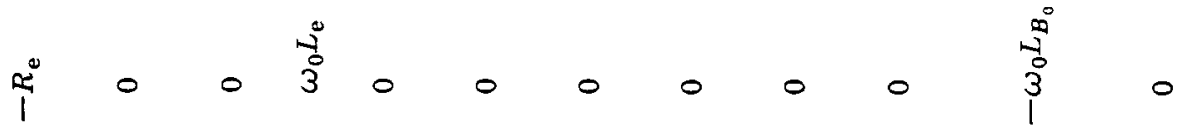

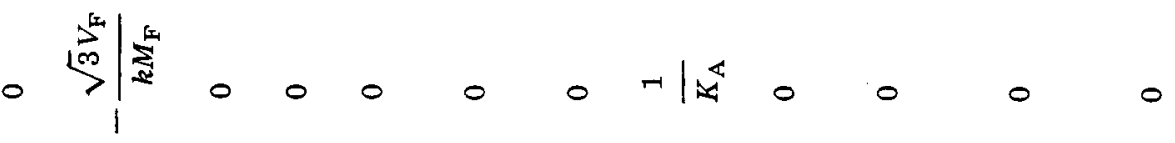

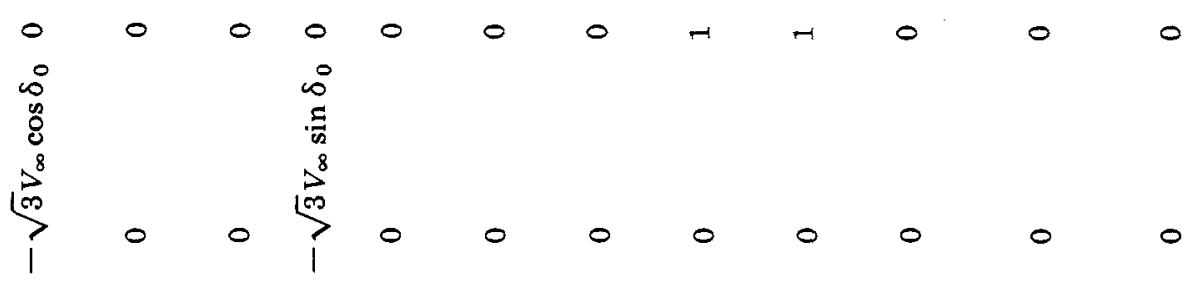

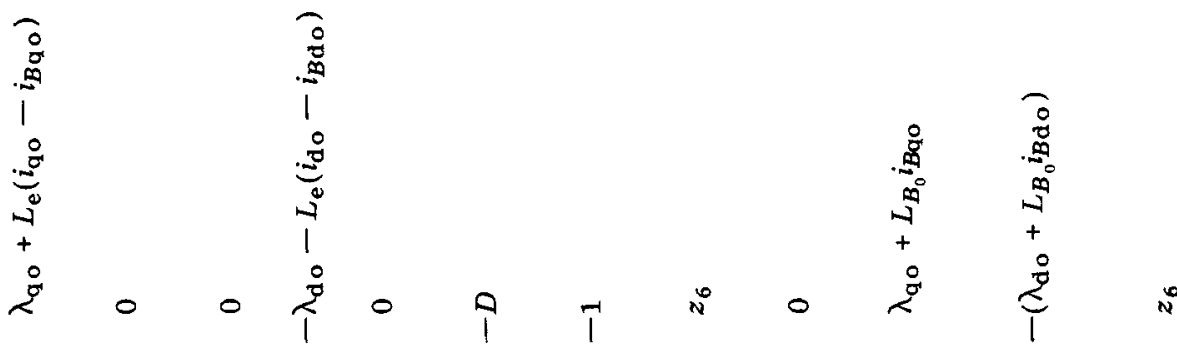

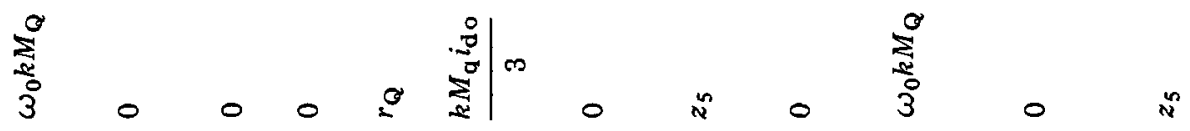

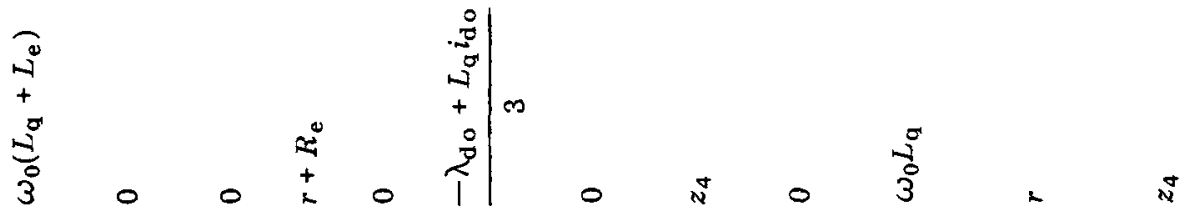

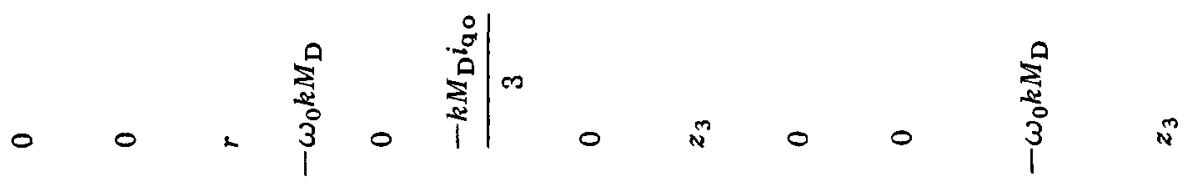

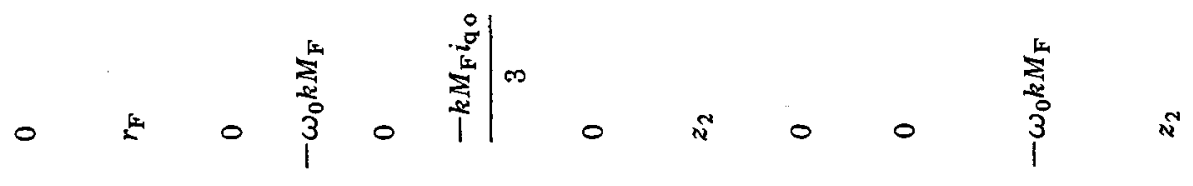

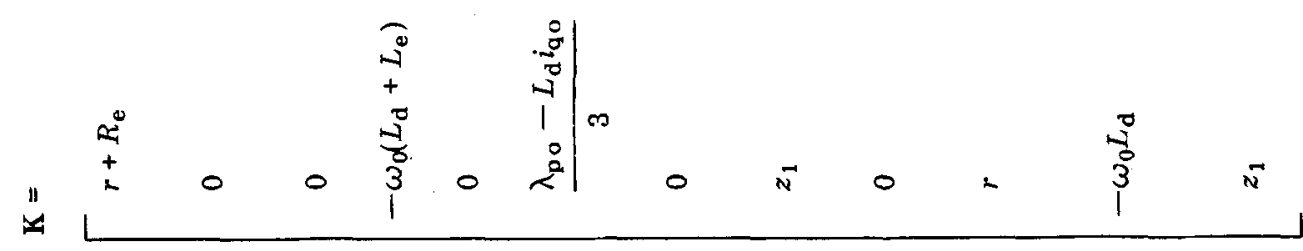




$\mathbf{M}=\left[\begin{array}{llllllllllll}L_{\mathrm{d}}+L_{\mathrm{e}} & k M_{\mathrm{F}} & k M_{\mathrm{D}} & 0 & 0 & 0 & 0 & 0 & 0 & -L_{\mathrm{e}} & 0 & 0 \\ k M_{\mathbf{F}} & L_{\mathrm{F}} & M_{\mathrm{R}} & 0 & 0 & 0 & 0 & 0 & 0 & 0 & 0 & 0 \\ k M_{\mathbf{D}} & M_{\mathrm{R}} & L_{\mathrm{D}} & 0 & 0 & 0 & 0 & 0 & 0 & 0 & 0 & 0 \\ 0 & 0 & 0 & L_{\mathbf{q}}+L_{\mathrm{e}} & k M_{\mathbf{Q}} & 0 & 0 & 0 & 0 & 0 & -L_{\mathbf{e}} & 0 \\ 0 & 0 & 0 & k M_{\mathbf{Q}} & L_{\mathbf{Q}} & 0 & 0 & 0 & 0 & 0 & 0 & 0 \\ 0 & 0 & 0 & 0 & 0 & -\tau_{\mathrm{j}} & 0 & 0 & 0 & 0 & 0 & 0 \\ 0 & 0 & 0 & 0 & 0 & 0 & 1 & 0 & 0 & 0 & 0 & 0 \\ w_{1} & w_{2} & w_{3} & w_{4} & w_{5} & 0 & 0 & 0 & \frac{T_{\mathrm{A}}}{K_{\mathrm{A}}} & 0 & 0 & 0 \\ 0 & 0 & 0 & 0 & 0 & 0 & 0 & T_{\mathrm{F}} & -K_{\mathbf{F}} & 0 & 0 & 0 \\ L_{\mathbf{d}} & k M_{\mathrm{F}} & k M_{\mathrm{D}} & 0 & 0 & 0 & 0 & 0 & 0 & L_{B_{0}} & 0 & 0 \\ 0 & 0 & 0 & L_{\mathbf{q}} & k M_{\mathbf{Q}} & 0 & 0 & 0 & 0 & 0 & L_{B_{\mathbf{0}}} & 0 \\ w_{1} & w_{2} & w_{3} & w_{4} & w_{5} & 0 & 0 & 0 & 0 & 0 & 0 & \frac{T_{\mathbf{r}}}{K_{\mathbf{r}}}\end{array}\right]$

$$
\begin{aligned}
& z_{1}=-k_{\mathrm{d}} r+k_{\mathrm{q}} \omega_{0} L_{\mathrm{d}} \\
& z_{2}=k_{\mathrm{q}} \omega_{0} k M_{\mathrm{F}} \\
& z_{3}=k_{\mathrm{q}} \omega_{0} k M_{\mathrm{D}} \\
& z_{4}=k_{\mathrm{d}} \omega_{0} L_{\mathrm{q}}+K_{\mathrm{q}} r \\
& z_{5}=k_{\mathrm{d}} \omega_{0} k M_{\mathrm{Q}} \\
& z_{6}=-k_{\mathrm{d}} \lambda_{\mathrm{qo}}+k_{\mathrm{q}} \lambda_{\mathrm{do}} \\
& w_{1}=k_{\mathrm{d}} L_{\mathrm{d}} \\
& w_{2}=k_{\mathrm{d}} k M_{\mathrm{F}} \\
& w_{3}=k_{\mathrm{d}} k M_{\mathrm{D}} \\
& w_{4}=k_{\mathrm{q}} L_{\mathrm{q}} \\
& w_{5}=k_{\mathrm{q}} k M_{\mathrm{Q}} \\
& k_{\mathrm{d}}=\frac{\sqrt{3} v_{\mathrm{do}}}{\left(v_{\mathrm{do}}{ }^{2}+v_{\mathrm{qo}}\right)^{1 / 2}} \\
& k_{\mathrm{q}}=\frac{\sqrt{3} v_{\mathrm{qo}}}{\left(v_{\mathrm{do}}{ }^{2}+v_{\mathrm{qo}}^{2}\right)^{1 / 2}} \\
& L_{B}=X_{\mathrm{T}}-\frac{1}{B_{C}+B_{L}} \\
& B_{0}=B_{L_{\mathrm{o}}}+\Delta B_{C}+B_{L_{0}} \\
& B_{1}
\end{aligned}
$$

$$
L_{B_{0}}=X_{\mathrm{T}}-\frac{1}{B_{0}}
$$

where $y=\Delta \omega$ is the output signal, and $u=V_{\mathrm{s}}$ is the control signal which can be expressed in the frequency domain as

$$
\begin{aligned}
U(s) & =\mathbf{H}(s) Y(s) \\
& =K_{\mathrm{P}}+\frac{K_{\mathrm{I}}}{s} Y(s)
\end{aligned}
$$

with $K_{\mathrm{P}}$ and $K_{\mathrm{I}}$ the gains of the PI static VAR controller. The main purpose here is to find a proper pair of parameters $K_{\mathrm{P}}$ and $K_{\mathrm{I}}$ to improve the damping of machine oscillations.

3. DESIGN OF A FIXED-GAIN STATIC VAR CONTROLLER USING THE EIGENVALUE ASSIGNMENT METHOD

In this section, the eigenvalue assignment method is employed for the design of a PI static VAR controller. In other words, the two parameters $K_{\mathrm{P}}$ and $K_{\mathrm{I}}$ are determined by shifting to more desirable locations a pair of eigenvalues associated with the oscillation mode with worst damping. The state equations in the frequency domain are first 
written by taking the Laplace transform of (1) and (2):

$$
\begin{aligned}
& s X(s)=\mathrm{A} X(s)+\mathrm{B} U(s) \\
& Y(s)=\mathrm{C} X(s)
\end{aligned}
$$

Equation (4) can be rearranged as follows:

$X(s)=(s \mathrm{I}-\mathrm{A})^{-1} \mathrm{~B} U(s)$

Combining eqns. (3), (5) and (6), we have

$X(s)=(s \mathrm{I}-\mathrm{A})^{-1} \mathrm{BH}(s) \mathrm{C} X(s)$

or

$$
\left[\mathbf{I}-(s \mathbf{I}-\mathbf{A})^{-1} \mathbf{B H}(s) \mathbf{C}\right] X(s)=0
$$

If $\lambda$ is the assigned eigenvalue of the closedloop system equipped with the PI static VAR controller, then

$\operatorname{det}\left[\mathbf{I}-(\lambda \mathbf{I}-\mathbf{A})^{-1} \mathbf{B H}(\lambda) \mathbf{C}\right]=0$

Using the identity [22]

$\operatorname{det}[\mathbf{I}-\mathbf{E} \cdot \mathbf{F}]=\operatorname{det}[\mathbf{I}-\mathbf{F} \cdot \mathbf{E}]$

eqn. (9) can be written as

$1-\mathbf{C}(\lambda \mathbf{I}-\mathbf{A})^{-1} \mathrm{BH}(\lambda)=0$

or

$$
H(\lambda)=\frac{1}{\mathbf{C}(\lambda I-A)^{-1} B}
$$

Therefore, a pair of simultaneous algebraic equations with the two unknown variables $K_{\mathrm{P}}$ and $K_{\mathrm{I}}$ can be obtained by substituting two prespecified eigenvalues $S=\lambda_{1}$ and $S=\lambda_{2}$ into (12). The two parameters of the PI static VAR controller are then computed from the solution of these two algebraic equations.

\section{DESIGN OF A MODEL REFERENCE ADAPTIVE CONTROLLER}

Consider a model reference adaptive controller (MRAC) as shown in Fig. 3. The reference model, which specifies the desired response characteristic for the system, and the plant are described by the equations

$\dot{\mathrm{X}}_{\mathrm{M} 1}=\mathrm{A}_{\mathrm{M} 1} \chi_{\mathrm{M} 1}+\mathrm{B}_{\mathrm{M} 1} U_{\mathrm{M} 1}$

$\dot{\boldsymbol{X}}_{\mathrm{P} 1}=\mathrm{A}_{\mathrm{P} 1} \boldsymbol{X}_{\mathrm{P} 1}+\mathrm{B}_{\mathrm{P} 1} U_{\mathrm{P} 1}+\mathrm{B}_{\mathrm{P} 1} U_{\mathrm{P} 2}$

The function of the adaptation mechanism is to generate the control signals

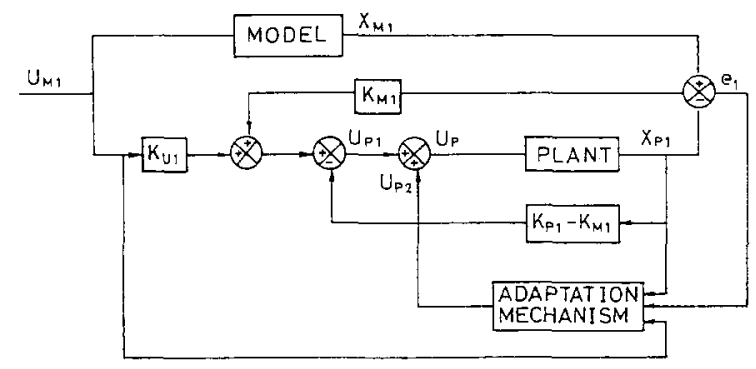

Fig. 3. Model reference adaptive control system.

$U_{\mathrm{P} 1}=-\mathrm{K}_{\mathrm{P} 1} \mathbf{X}_{\mathrm{P} 1}+\mathrm{K}_{\mathrm{M} 1} X_{\mathrm{M} 1}+\mathrm{K}_{\mathrm{U} 1} U_{\mathrm{M} 1}$
$U_{\mathrm{P} 2}=\Delta \mathrm{K}_{\mathrm{P}}\left(t, e_{1}\right) \boldsymbol{X}_{\mathrm{P} 1}+\Delta \mathrm{K}_{\mathrm{U}}\left(t, e_{1}\right) U_{\mathrm{M} 1}$

in order to assure that the error signal

$e_{1}=\chi_{\mathrm{M} 1}-X_{\mathrm{P} 1}$

would finally vanish in the steady state. In other words, the following condition must be met:

$\lim _{t \rightarrow \infty} e_{1}(t)=0$

under disturbance conditions.

One must first verify that the linear model following control system $\left(U_{\mathrm{P} 2}=0\right)$ satisfies the 'perfect model following' conditions

$\left(\mathrm{I}-\mathrm{B}_{\mathrm{P} 1} \mathrm{~B}_{\mathrm{P} 1}{ }^{+}\right) \mathrm{B}_{\mathrm{M} 1}=0$

$\left(\mathrm{I}-\mathbf{B}_{\mathrm{P} 1} \mathbf{B}_{\mathrm{P} 1}{ }^{+}\right)\left(\mathrm{A}_{\mathrm{M} 1}-\mathrm{A}_{\mathrm{P} 1}\right)=0$

where $\mathbf{B}_{\mathrm{P}_{1}}{ }^{+}$is the Penrose pseudo-inverse of $\mathbf{B}_{\mathrm{P} 1}$ :

$\mathrm{B}_{\mathrm{P} 1}{ }^{+}=\left(\mathrm{B}_{\mathrm{P} 1}{ }^{\mathrm{T}} \mathrm{B}_{\mathrm{P} 1}\right)^{-1} \mathrm{~B}_{\mathrm{P} 1}{ }^{\mathrm{T}}$

The MRAC is a generalization of a fixedgain PI controller in which a 'proportional plus integral' adaptation law for $\Delta K_{\mathrm{P}}(t, e)$ and $\Delta K_{\mathrm{U}}(t, e)$ is employed. Thus we have [11]

$$
\begin{aligned}
\Delta \mathbf{K}_{\mathrm{P}}\left(t, e_{1}\right)= & \int_{0}^{t} \tilde{\mathbf{L}} \boldsymbol{v}\left(\mathbf{Q} \mathbf{X}_{\mathrm{P} 1}\right)^{\mathrm{T}} \mathrm{d} \tau+\mathbf{L} \boldsymbol{v}\left(\mathbf{Q} \mathbf{X}_{\mathrm{P} 1}\right)^{\mathrm{T}} \\
& +\Delta \mathbf{K}_{\mathrm{P}}(0)
\end{aligned}
$$

$$
\begin{aligned}
\Delta \mathbf{K}_{\mathrm{U}}(t, e)= & \int_{0}^{t} \tilde{\mathbf{M}} \boldsymbol{v}\left(\mathbf{R} U_{\mathrm{M} 1}\right)^{\mathbf{T}} \mathrm{d} \tau+\operatorname{M} v\left(\mathbf{R} U_{\mathrm{M} 1}\right)^{\mathrm{T}} \\
& +\Delta \mathbf{K}_{\mathrm{U}}(0)
\end{aligned}
$$

where

$v=\mathrm{D}_{1} e_{1}$ 
is a generalized error and $\mathbf{L}, \tilde{\mathbf{L}}, \mathbf{M}, \tilde{\mathbf{M}}, \mathbf{Q}$ and $\mathbf{R}$ are positive definite matrices of appropriate dimension.

In order that the system be asymptotically hyperstable, the transfer matrix

$\mathrm{Z}(s)=\mathrm{D}_{1}\left(s \mathrm{I}-\mathbf{A}_{\mathrm{M} 1}+\mathbf{B}_{\mathrm{P}_{1}} \mathrm{~K}_{\mathrm{M} 1}\right)^{-1} \mathbf{B}_{\mathrm{P} 1}$

must be strictly positive real. This implies that $\left(A_{M 1}-B_{P_{1}} K_{M 1}\right)$ must be a Hurwitz matrix and that $D_{1}$ is given by

$\mathrm{D}_{1}=\mathrm{B}_{\mathrm{P}_{1}}{ }^{\mathrm{T}} \mathbf{P}$

where $\mathbf{P}$ is a positive definite matrix solution of the Lyapunov equation

$$
\left(A_{M 1}-B_{P 1} K_{M 1}\right)^{T} P+P\left(A_{M 1}-B_{P 1} K_{M 1}\right)=-H
$$

$\mathbf{H}$ being an arbitrary positive definite (or semidefinite) matrix. For the particular cases in which $\mathbf{K}_{\mathrm{M} 1}$ is given by

$\mathbf{K}_{\mathrm{M}_{1}}=\mathbf{B}_{\mathrm{P}_{1}}{ }^{\mathrm{T}} \tilde{\mathbf{P}}$

where $\widetilde{\mathbf{P}}$ is the solution of the algebraic Ricatti equation

$\widetilde{\mathbf{P}} \mathbf{A}_{\mathrm{M} 1}+\mathbf{A}_{\mathrm{M} 1}{ }^{\mathrm{T}} \tilde{\mathbf{P}}-\tilde{\mathbf{P}} \mathbf{B}_{\mathrm{P} 1} \mathbf{B}_{\mathrm{P} 1}{ }^{\mathrm{T}} \tilde{\mathbf{P}}+\tilde{\mathbf{H}}=\mathbf{0}$

the gains $\mathbf{K}_{\mathrm{P}_{1}}$ and $\mathbf{K}_{\mathrm{U} 1}$ are determined by

$\mathrm{K}_{\mathrm{P} 1}=\mathrm{B}_{\mathrm{P} 1}{ }^{+}\left(\mathrm{A}_{\mathrm{P} 1}-\mathrm{A}_{\mathrm{M} 1}+\mathrm{B}_{\mathrm{P} 1} \mathrm{~K}_{\mathrm{M} 1}\right)$

$\mathbf{K}_{\mathrm{U} 1}=\mathbf{B}_{\mathrm{P} 1}{ }^{+} \mathbf{B}_{\mathrm{M} 1}$

\section{EXAMPLE}

Consider a synchronous generator connected to a large power system through a double-circuit transmission line as shown in Fig. 1. The parameters of the system are as follows $[1,13]$.

Synchronous generator

$$
\begin{aligned}
& \omega_{\mathrm{R}}=377 \mathrm{rad} \mathrm{s}^{-1} \\
& L_{\mathrm{d}}=1.7 \text { p.u., } \\
& L_{\mathrm{F}}=1.65 \text { p.u. } \\
& L_{\mathrm{D}}=1.605 \text { p.u., } \quad L_{\mathrm{q}}=1.64 \text { p.u. } \\
& k M_{\mathrm{F}}=k M_{\mathrm{D}}=M_{\mathrm{R}}=1.55 \text { p.u. } \\
& k M_{\mathrm{Q}}=1.49 \text { p.u. } \\
& l_{\mathrm{d}}=l_{\mathrm{q}}=0.15 \text { p.u. } \\
& r=0.001096 \text { p.u., } \quad r_{\mathrm{F}}=0.000742 \text { p.u. }
\end{aligned}
$$

$$
\begin{array}{ll}
r_{\mathrm{D}}=0.0131 \text { p.u., } & r_{\mathrm{Q}}=0.054 \text { p.u. } \\
H=2.37 \mathrm{~s}, & D=0 \\
R_{\mathrm{e}}=0.02 \text { p.u., } & L_{\mathrm{e}}=0.4 \text { p.u. }
\end{array}
$$

Voltage regulator and exciter

$$
\begin{array}{ll}
T_{\mathrm{A}}=0.05 \mathrm{~s}, & K_{\mathrm{A}}=400 \\
T_{\mathrm{F}}=1 \mathrm{~s}, & K_{\mathrm{F}}=0.025
\end{array}
$$

\section{Static VAR compensator}

$X_{\mathrm{T}}=0.08$ p.u.

$$
\begin{array}{ll}
K_{\mathrm{r}}=50, & T_{\mathrm{r}}=0.15 \mathrm{~s} \\
V_{\mathrm{s} \max }=0.12 \text { p.u., } & V_{\mathrm{s} \min }=-0.12 \text { p.u. } \\
\Delta B_{L \max }=0.375 \text { p.u., } & \Delta B_{L \min }=-0.4 \text { p.u. } \\
B_{C}=0.625 \text { p.u., } & B_{L_{0}}=-0.6 \text { p.u. }
\end{array}
$$

The eigenvalues of the system under the generator loading condition of $P=1.0$ p.u. and $Q=0.62$ p.u. are listed in Table 1 and it can be observed from the Table that, for the system without a PI controller, the damping of the electromechanical mode, which is described by the eigenvalues $-0.161 \pm j 9.476$, is very poor. Therefore, a supplementary PI controller is required if better damping characteristics for this mode are to be achieved. With a damping ratio of 0.32 , two prespecified eigenvalues, $-2.578 \pm \mathrm{j} 8.103$, were assigned for the mechanical mode. With these eigenvalues substituted into (12), the desired PI controller parameters $K_{\mathrm{P}}=3.8$ and $K_{\mathrm{I}}=0.055$ are obtained.

For the model reference adaptive SVC, the linearized model at the nominal operating point of $P=1.0$ p.u. and $Q=0.62$ p.u. is chosen as the reference.

\section{TABLE 1}

System eigenvalues at $P=1.0$ p.u. and $Q=0.62$ p.u.

\begin{tabular}{ll}
\hline $\begin{array}{l}\text { Open-loop system } \\
\text { (without PI controller) }\end{array}$ & $\begin{array}{l}\text { Closed-loop system } \\
\text { (with PI controller) }\end{array}$ \\
\hline$-0.161 \pm \mathrm{j} 9.476$ & $-2.578 \pm \mathrm{j} 8.103^{\mathrm{a}}$ \\
$-6.194 \pm \mathrm{j} 377.389$ & $-6.986 \pm \mathrm{j} 377.411$ \\
$-10.890 \pm \mathrm{j} 376.112$ & $-10.360 \pm \mathrm{j} 376.008$ \\
$-39.884 \pm \mathrm{j} 42.303$ & $-39.617 \pm \mathrm{j} 42.594$ \\
$-32.530 \pm \mathrm{j} 4.825$ & -28.027 \\
-2.547 & -34.611 \\
-1.007 & -0.982 \\
& -0.166 \\
\hline
\end{tabular}

${ }^{a}$ Exactly assigned eigenvalues. 


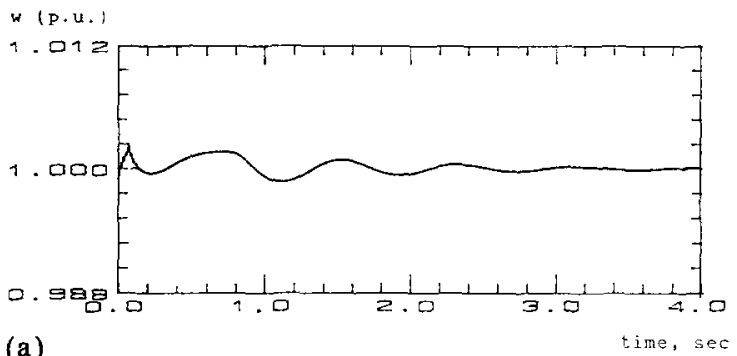

(a)

w (p.U.)

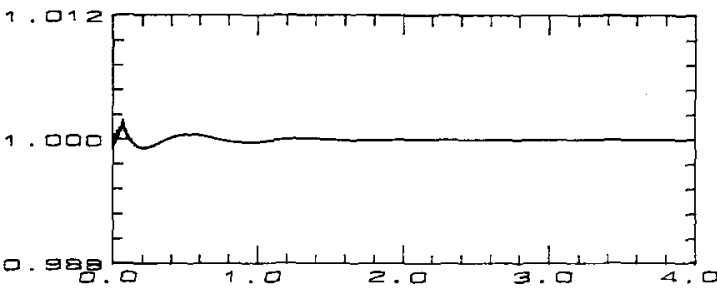

(b)

Fig. 4. Angular speed variations for loading condition of $P=0.5$ p.u.: (a) PI controller; (b) MRAC.

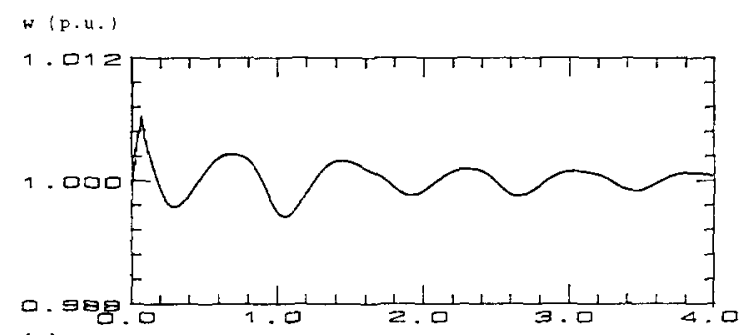

(a)
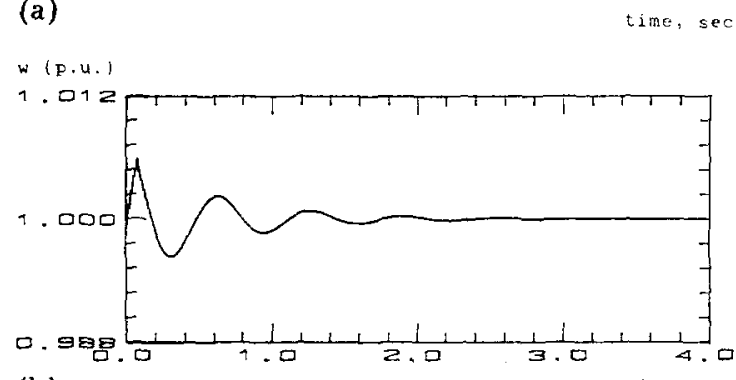

(b)

time, sec

Fig. 5. Angular speed variations for loading condition of $P=1.0$ p.u.: (a) PI controller; (b) MRAC.

The weighting matrices $\mathrm{H}, \mathbf{Q}, \mathbf{L}$ and $\widetilde{\mathrm{L}}$ used in the simulation are

$$
\begin{aligned}
& \mathbf{H}=\operatorname{diag}\left[\begin{array}{llllllllllll}
1 & 1 & 1 & 1 & 1 & 10^{3} & 10^{3} & 1 & 1 & 1 & 1 & 10^{3}
\end{array}\right] \\
& \mathbf{Q}=\operatorname{diag}\left[\begin{array}{llllllllllll}
1 & 1 & 1 & 1 & 1 & 10^{2} & 10^{2} & 1 & 1 & 1 & 1 & 10^{2}
\end{array}\right] \\
& \tilde{\mathbf{L}}=5 \times 10^{20} \\
& \mathbf{L}=8 \times 10^{25}
\end{aligned}
$$

In order to demonstrate the effectiveness of the proposed MRAC SVC over a wide range of operating conditions, digital simula-

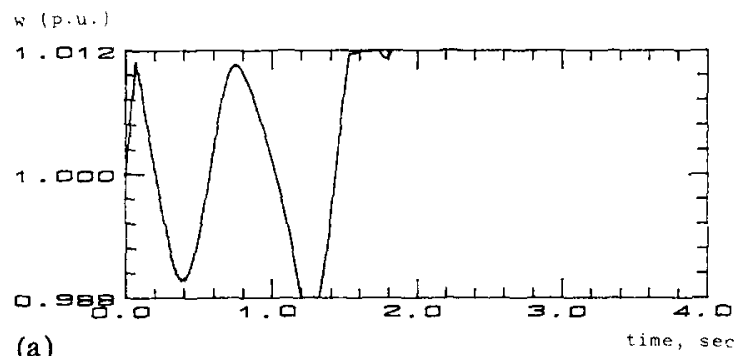

(a)

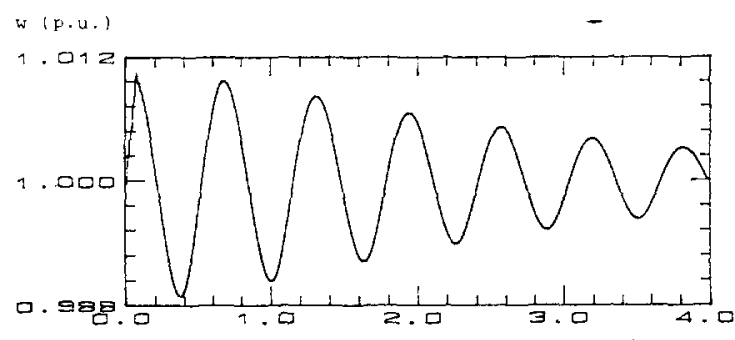

(b)

Fig. 6. Angular speed variations for loading condition of $P=1.5$ p.u.: (a) PI controller; (b) MRAC.

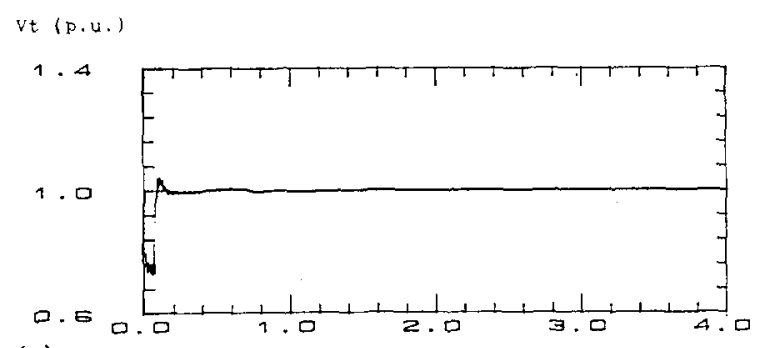

(a)

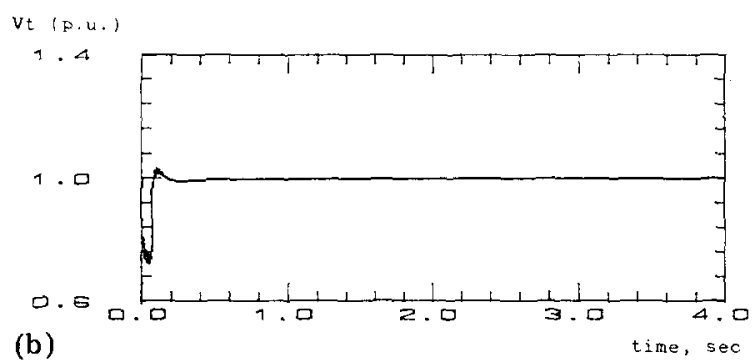

Fig. 7. Terminal voltage variations for loading condition of $P=0.5$ p.u.: (a) PI controller; (b) MRAC.

tions were performed for the generator subject to a four-cycle three-phase fault at the midpoint of one of the two transmission lines. Three different loading conditions, $P=0.5$ p.u., $P=1.0$ p.u., and $P=1.5$ p.u., were considered in the simulation. The generator angular speed variations $\Delta \omega$ obtained by using the fixed-gain PI and MRAC static VAR compensators are compared in Figs. $4-6$ while the terminal voltage variations $\Delta V_{\mathrm{t}}$ are compared in Figs. $7-9$, respectively. 


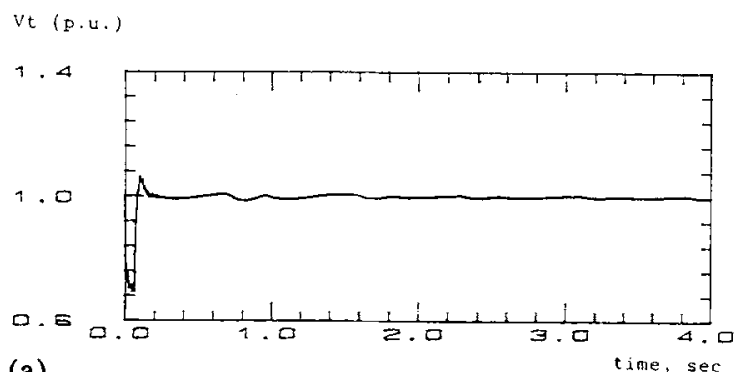

(a)

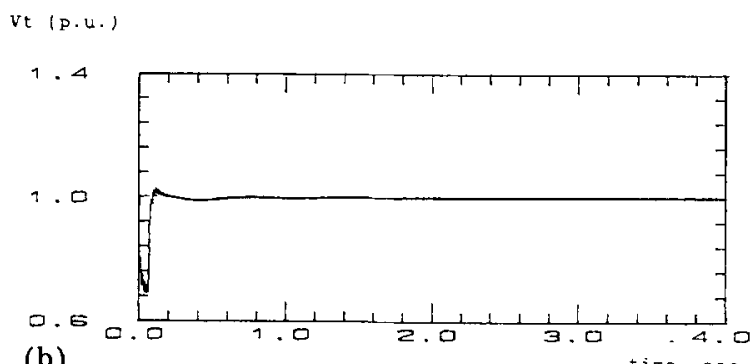

(b)

Fig. 8. Terminal voltage variations for loading condition of $P=1.0$ p.u.: (a) PI controller; (b) MRAC.

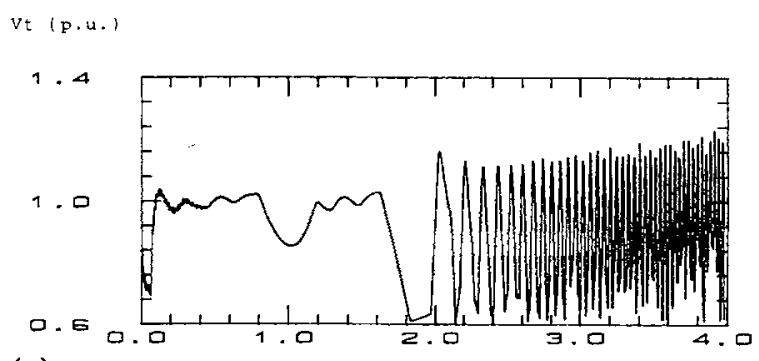

(a)
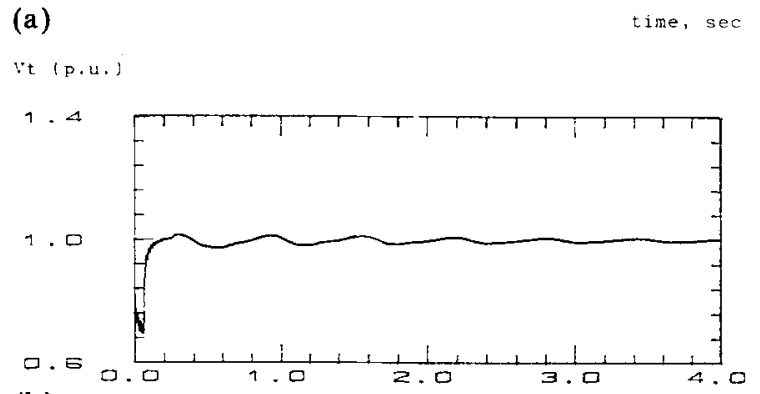

(b)

Fig. 9. Terminal voltage variations for loading condition of $P=1.5$ p.u.: (a) PI controller; (b) MRAC.

On comparing these Figures, it is observed that the MRAC SVC can provide better dynamic performance than the fixed-gain PI SVC. Only minor deviations in the terminal voltage have been experienced by both static VAR compensators. Moreover, the stability margin can be expanded by the MRAC since the generator with the MRAC SVC can remain stable at the loading condition of $P=1.5$ p.u., while that with the fixed-gain PI SVC can not.

\section{CONCLUSIONS}

The design of a static VAR compensator for the damping of a synchronous generator has been examined by using a fixed-gain PI controller and a model reference adaptive controller. It is found that the MRAC SVC can offer better dynamic responses than the PI SVC over a wide range of loading conditions. Moreover, the MRAC SVC can provide a larger transient stability margin than the PI SVC. Both controllers can maintain a smooth voltage profile during disturbance conditions.

\section{NOMENCLATURE}

$\mathbf{A}, \mathbf{B}, \mathbf{C}, \mathbf{\Gamma}$
$B_{C}$
$B_{L}$
$D$
$E_{\mathrm{FD}}$
$H$
$i_{B}$
$i_{\mathrm{d}}, i_{\mathrm{q}}$
$i_{\mathrm{D}}, i_{\mathrm{Q}}$
$i_{\mathrm{F}}$
$k M_{\mathrm{F}}=k M_{\mathrm{D}}=M_{\mathrm{R}}$
$k M_{\mathrm{Q}}$
$K_{\mathrm{A}}$
$K_{\mathrm{F}}$
$K_{\mathrm{P}}, K_{\mathrm{I}}$
$K_{\mathrm{r}}$
$l_{\mathrm{d}}, l_{\mathrm{q}}$

system matrices

capacitive susceptance of SVC

inductive susceptance of SVC

damping coefficient

exciter field voltage

inertia constant

SVC current

stator d-axis and q-axis currents

$\mathrm{d}$-axis and $\mathrm{q}$-axis damper winding currents

field winding current

$=L_{\mathrm{d}}-l_{\mathrm{d}}$

$=L_{\mathrm{q}}-l_{\mathrm{q}}$

regulator gain

stabilizing transformer gain

PI controller gain

SVC gain

$\mathrm{d}$-axis and q-axis stator winding leakage inductances

$L_{\mathrm{d}}, L_{\mathrm{q}}$

$L_{\mathrm{D}}, L_{\mathbf{Q}}$

$L_{\mathrm{e}}$

$L_{\mathrm{F}}$

$r$

$r_{\mathrm{D}}, r_{\mathbf{Q}}$

$r_{\mathrm{F}}$
$R_{\mathrm{e}}$

$T_{\mathrm{A}}$

$T_{\mathrm{F}}$ $\mathrm{d}$-axis and q-axis stator winding inductances

$\mathrm{d}$-axis and $\mathrm{q}$-axis damper winding inductances external inductance field winding inductance stator resistance $\mathrm{d}$-axis and $\mathrm{q}$-axis damper winding resistances

field resistance external resistance regulator time constant stabilizing transformer time constant 


$\begin{array}{ll}T_{\mathrm{m}} & \text { mechanical input } \\ T_{\mathrm{r}} & \text { SVC time constant } \\ T_{\mathrm{w}} & \begin{array}{l}\text { washout time constant } \\ \text { d-axis and q-axis stator } \\ v_{\mathrm{d}}, v_{\mathrm{q}}\end{array} \\ V_{\mathrm{REF}} & \begin{array}{l}\text { voltages } \\ \text { reference voltage for gen- } \\ \text { erator }\end{array} \\ V_{\mathrm{s}} & \text { SVC output } \\ V_{\mathrm{ST}} & \text { stabilizing transformer out- } \\ & \text { put } \\ V_{t} & \text { generator terminal voltage } \\ V_{\infty} & \text { infinite bus voltage } \\ X_{\mathrm{T}} & \text { transformer reactance of } \\ & \text { SVC } \\ \delta & \text { torque angle } \\ \omega & \text { angular speed } \\ \omega_{\mathrm{R}} & \text { rated angular speed }\end{array}$

\section{REFERENCES}

1 P. M. Anderson and A. A. Fouad, Power System Control and Stability, Iowa State University Press, Ames, IA, 1977.

2 E. V. Larsen and D. A. Swann, Applying power system stabilizers, IEEE Trans., PAS-100 (1981) $3017-3046$.

3 Y. Y. Hsu, S. S. Shyue and C. C. Su, Low frequency oscillations in longitudinal power systems: experience with dynamic stability of Taiwan power system, IEEE Trans., PWRS-2 (1987) $92 \cdot 100$.

4 W. C. Chan and Y. Y. Hsu, An optimal variable structure stabilizer for power system stabilization, IEEE Trans., PAS-102 (1983) 1738 - 1746.

$5 \mathrm{Y}$. Y. Hsu and C. Y. Hsu, Design of a proportional-integral power system stabilizer, IEEE Trans., PWRS-1 (1986) 46 - 53.

6 C. J. Wu and $Y$. Y. Hsu, Self-tuning excitation control for synchronous machine, IEEE Trans., AES-22 (1986) 389 - 394.

7 Y. Y. Hsu and C. C. Su, Application of power system stabilizer on a system with pumped storage plant, IEEE PES Winter Meeting, New Orleans, 1987, Paper No. 87 WM 049-0.

8 G. Ledwich, Control algorithms for shunt VAR systems, Electr. Power Syst. Res., 6 (1983) 141 146.

9 S. C. Kapoor, Dynamic stability of long transmission systems with static compensators and and synchronous machines, IEEE Trans., PAS-98 (1979) $124-134$.

10 M. Z. El-Sadek and A. E. Hammad, Optimization of parameters of static compensator systems, Canadian Communication and Power Conf., 1980, pp. $10 \cdot 13$.

11 S. C. Kapoor, Dynamic stability of static compensator-synchronous generator combination, IEEE Trans., PAS-100 (1981) 1694 - 1702.

12 H. E. Schweickardt, G. Romegialli and K. Reichert, Closed-loop control of static VAR sources (SVS) on EHV transmission lines, IEEE PES Winter Meeting, New York, 1978, Paper No. A78 135-6.

13 H. C. Barnes, Modeling of static shunt VAR systems (SVS) for system analysis, Electra, 51 (1977) $45 \cdot 74$.

14 D. E. Martin, SVC considerations for system damping, Symp. on Static VAR Compensators, IEEE PES Winter Meeting, New York, 1987.

15 I. Hosono, M. Yano, S. Takeda, S. Yuya and S. Sueda, Suppression and measurement of arc furnace flicker with a large static VAR compensator, IEEE Trans., PAS-98 (1979) 2276 2284.

16 R. L. Hauth, T. Hurnann and R. J. Newell, Application of a static var system to regulate system voltage in western Nebraska, IEEE Trans., PAS-97 (1978) 1955 - 1964.

$17 \mathrm{M}$. Brucoli, F. Torelli and M. Trovato, A decentralized control strategy for dynamic shunt VAR compensation in interconnected power systems, Proc. Inst. Electr. Eng., Part C, 132 (1985) 229 236.

18 A. Olwegard, K. Wlave, G. Waglund, H. Frank and S. Torseng, Improvement of transmission capacity by thyristor controlled reactive power, IEEE Trans., PAS-100 (1981) 3930 - 3939.

19 R. T. Byerly, D. T. Poznaniak and E. R. Taylor, Static reactive compensation for power transmission systems, IEEE Trans., PAS-101 (1982) $3997-4005$.

20 R. M. Mathur and A. E. Hammad, Transient and small signal stability of a superconducting turbogenerator operating with thyristor controlled static compensator, IEEE Trans., PAS-98 (1979) 1937 - 1946.

21 L. Gyugi and E. R. Taylor, Jr., Characteristics of static, thyristor-controlled shunt compensator for power transmission system applications, IEEE Trans., PAS-99 (1980) 1795 - 1804.

22 T. Kailath, Linear Systems, Prentice-Hall, Englewood Cliffs, NJ, 1980 , p. 651.

23 I. D. Landau and B. Control, Adaptive model following systems for flight control and simulation, J. Aircraft, 9 (1972) $668-674$.

24 B. Courtiol and I. D. Landau, High speed adaptation system for controlled electrical drives, Automatica, 11 (1975) 119 - 127. 